\title{
La conformación de la Colección de fotografía del Museo de Bellas Artes de Bilbao
}

\author{
DOLORS FABRA ANTON
}

Universidad Complutense de Madrid

Recibido: 09-05-2019

Aprobado: 11-07-2019

\section{RESUMEN}

El presente artículo se basa en las conclusiones de la Tesis doctoral La Colección de Fotografía del Museo de Bellas Artes de Bilbao (1914-2014): estudio, catalogación y análisis ${ }^{1}$. Más allá del estudio de los fondos fotográficos que custodia el Museo, la investigación plantea cuestiones adyacentes que aluden a la problemática de la conservación del Patrimonio fotográfico, como a las dificultades que ha tenido en su introducción en las instituciones, así como en lo que atañe a los museos. Con ello se perfila el contexto en el que ubicar el papel que tuvo el Bilboko Arte Ederren Museoa=Museo de Bellas Artes de Bilbao en su principal etapa de conformación de la Colección de fotografía, desde 1980 hasta 1997. Por otro lado, se trata de promover los fondos conservados en el Museo, como aportación a la cartografía del Patrimonio fotográfico español y a la problemática de su indefinición.

PALABRAS CLAVE: Fotografía / colección / museo / Bilbao.

\section{ABSTRACT}

This article is based on the conclusions of the doctoral thesis The Collection of Photography of the Bilbao Fine Arts Museum (1914-2014): Estady, Cataloguing and Analysis ${ }^{2}$. Beyond the study of the photographic collections that the Museum keeps, the research raises adjacent issues that allude to the problematic of the conservation of the photographic heritage, as well as the difficulties that the medium had in its introduction in the institutions, especially as regards to the museums. With this, it is outlined with context in which to locate the paper that the Museum of Fine Arts of Bilbao in its main stage of conformation

1 Dirigida por José Manuel Susperregui y Concha Casajús, fue defendida en la Universidad Complutense de Madrid el 20 de febrero del 2019. Asimismo, la investigación tuvo como punto de partida la Beca BBK-Museo, que me fue concedida durante los años 2014 hasta 2016, con el fin de catalogar y hacer un primer estudio de la Colección de fotografía del Bilboko Arte Ederren Museoa=Museo de Bellas Artes de Bilbao.

2 Directed by José Manuel Susperregui and Concha Casajús, it was defended at the Complutense University of Madrid on February 20, 2019. Likewise, the research had as starting point the BBK-Museum Scholarship, which was granted to me during the years 2014 to 2016, in order to catalog and make a first study of the Collection of Photography of the Museum of Fine Arts of Bilbao. 
of the Photography Collection, from 1980 to 1997 . On the other hand, it is sought to give to know the funds preserved in the Museum, as a contribution to the cartography of the Spanish photographic heritage and the problems of its lack of definition.

KEY WORDS: Photography / collection / museum / Bilbao.

$* * *$

\section{Omisiones en la gestión del Patrimonio fotográfico español}

La conservación, promoción y difusión del Patrimonio Histórico Español está garantizada por la Constitución Española, en varios de sus artículos, y está regulada por la ley 16/1985. Esta última define el Patrimonio desde una perspectiva genérica que permite una interpretación amplia del mismo.

Esta flexibilidad en su definición comporta una ventaja sobre la posibilidad de ampliar los bienes a conservar. Esta misma flexibilidad también afecta a las condiciones y a las medidas a adoptar, algo que perjudica negativamente cuando no hay un compromiso firme de poner en práctica la teoría plasmada sobre el papel. Con ello, la libertad de interpretación y de actuación fácilmente pueden caer en una dejadez por parte de las instituciones en el necesario amparo de una parte del Patrimonio, como sucede frecuentemente con la fotografía.

Como indicativo inapelable de la falta de atención hacia la fotografía, no hay más que ver la fecha de creación de un Plan Nacional de Conservación del Patrimonio Fotográfico, en el año 2015³. Aunque su redacción debe ser celebrada como un avance indispensable hacia la creación de un marco de protección y fomento de la fotografía, las actuaciones de los entes no parecen ser las adecuadas para alcanzar los planteamientos propuestos en dicho Plan. Así, se echan a faltar medidas concretas para su aplicación, y el establecimiento de unas directrices concretas que impliquen a los organismos competentes.

\footnotetext{
3 Plan Nacional de Conservación del Patrimonio Fotográfico, Secretaría General Técnica. Subdirección General de Documentación y Publicaciones, [S.1.], 2015. [10/08/18]. Disponible en: https://www.scribd.com/document/324267024/ PLAN-NACIONAL-DE-CONSERVACIO-N-DEL-PATRIMONIO-FOTOGRA-FICO.
} 
Consecuencia de ello es que el conocimiento de las colecciones y archivos existentes en el Estado, en el que incide el Plan como un requisito previo e imprescindible para su control, así como para hacer cualquier tipo de balance sobre el mismo, no ha sido resuelto todavía.

Con este fin nació en $2010 \mathrm{dFoto}$, un proyecto que abordaba la tarea de registrar los archivos y fondos fotográficas conservados en el Estado, a modo de base de datos ${ }^{4}$. Si bien esta base de datos se mantiene activa en Internet, las labores de recopilación e investigación se paralizaron, dando al traste con el esfuerzo inicial que prometía suplir esta carencia. Por otro lado, contamos con Hispania, un portal de acceso al patrimonio digitalizado de los archivos, bibliotecas y museos españoles, si bien su labor como intermediador deja fuera todo aquel patrimonio que no haya sido digitalizado, así como las colecciones privadas, además de no tratarse de un recurso dedicado específicamente a la fotografía 5 .

Hasta el día de hoy, únicamente son dos las autonomías que han concluido esta tarea, la primera fue Cataluña, en 1996, plasmada en el Llibre Blanc del patrimoni fotogràfic a Catalunya, y la segunda las Islas Baleares, con la Guia d'arxius, col-leccions i fons fotogràfics i cinematogràfics de les Balear, 1840-1967, del 2004. También Canarias tomó la iniciativa de llevar a cabo una Guía-inventario de fondos y colecciones fotográficas de Canarias, emprendida entre el 2009 y el 2013, que desgraciadamente no contó con el apoyo económico suficiente para su publicación y difusión. Igualmente, el Gobierno Vasco inició en 2016 una labor de registro de las colecciones y fondos de la Comunidad a través de la red académica i2basque, cuyos resultados de momento no están disponibles. Por último, como ejemplo de una empresa privada, el Photomuseum de Zarautz propuso la creación de una base de datos, Isurkide, que recogiera toda aquella información que estuviera relacionada con la fotografía en el País Vasco.

Este esbozo del panorama sombrío de lo que debería ser el fundamentopara una primera evaluación del Patrimonio fotográfico evidencia las carencias en la apli-

dFoto. Directorio de colecciones de fotografia en España, [03/05/2019]: http://dfoto.info/

5 Hispania. Directorio nacional de recursos digitales, [03/05/2019]: http://hispana.mcu.es/es/inicio/inicio.do 
cación de unas políticas efectivas dirigidas a materializar los planteamientos del Plan Nacional del Patrimonio Fotográfico. Un déficit que viene dado, principalmente, por el desinterés por parte de los gestores, principalmente políticos, así como la falta de conciencia por el Patrimonio, en general, como una prioridad en las políticas, que provoca, entre otras cuestiones, el desabastecimiento de recursos económicos para la concreción de medidas.

Si bien estas consideraciones son aplicables a otros ámbitos patrimoniales, la fotografía sufre un agravio comparativo respecto a otros bienes, que le viene dado en parte por la falta de consideración que ha tenido a lo largo de la historia, así como por la diversidad de organismos que se dedican a su preservación, que son regidos por distintas normas de actuación.

\section{La fotografía en el mundo del arte}

Antes de abordar las reflexiones sobre la entrada de la fotografía en las instituciones, es conveniente hacer una breve descripción del medio. Michel Frizot define la fotografía como un conjunto de imágenes sumamente dispares que tienen en común el hecho de haber sido creadas por la acción de la luz sobre una superficie sensible ${ }^{6}$. Se trata de una definición amplia, que incluye una extensa gama de objetos, materiales y procedimientos. Entre ellos, el cliché y el positivo o copia, que se reproduce a partir del primero, que pueden tener soportes en distintos materiales como el plástico, el vidrio, el papel o el fichero digital.

La fotografía también se caracteriza por su versatilidad y polivalencia, rasgos que influyen tanto en su presencia en distintos ámbitos de la vida social y cultural, abarcando usos y aplicaciones diversas, como en la imposibilidad de aunarla, en su totalidad, bajo un mismo enfoque teórico. Esta peculiaridad dificulta asir la esencia misma de la fotografía, lo cual comporta las múltiples discordancias que existen a la hora de definirla según unos patrones fijos.

\footnotetext{
6 "....it is an ensemble of highly disparate images which possess in common the fact that they were created by the action of light on a sensitive surface" (traducción de la autora; en adelante no se indicarán las traducciones propias. FRIZOT, M., A New History of Photography, Könemann, Köln, 1998, p. 11.
} 


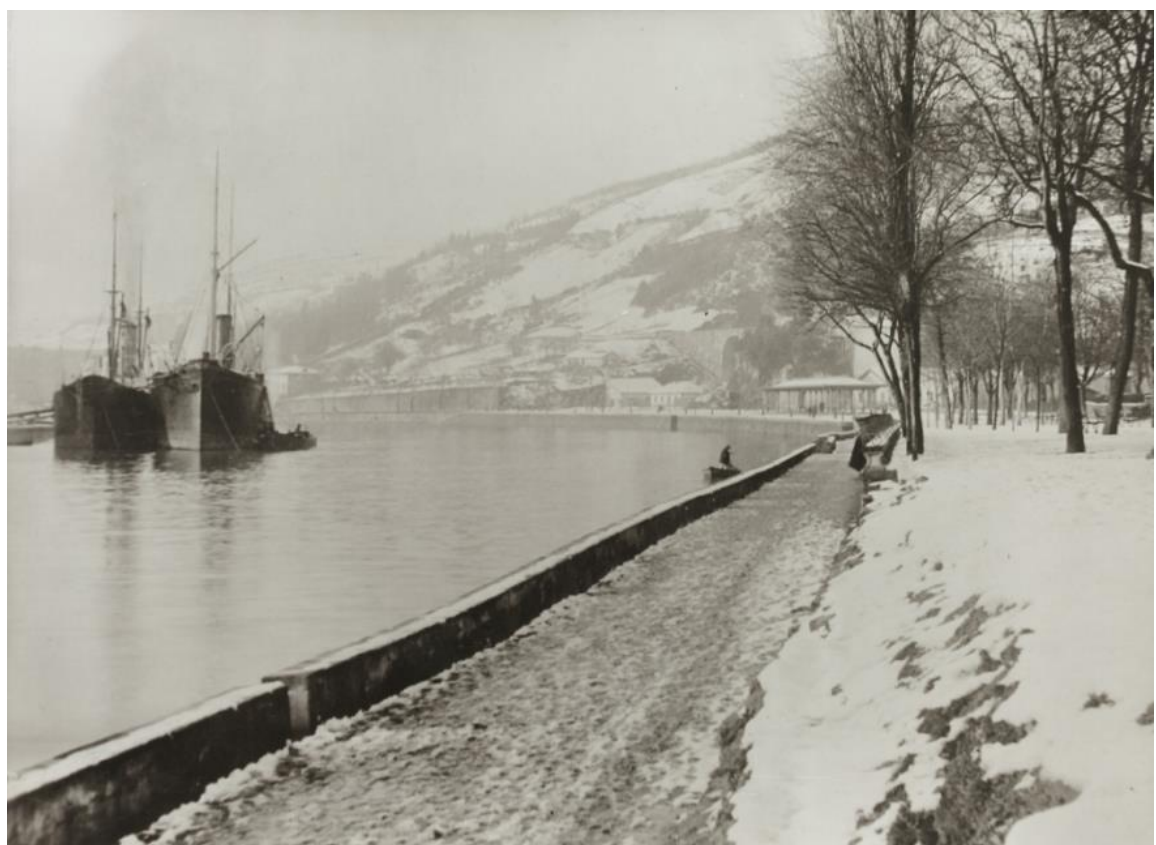

Fig. 1. Enrique Epalza, [Campo Volantín, a la altura de La Salve], ppios s, XX, Museo de Bellas Artes de Bilbao

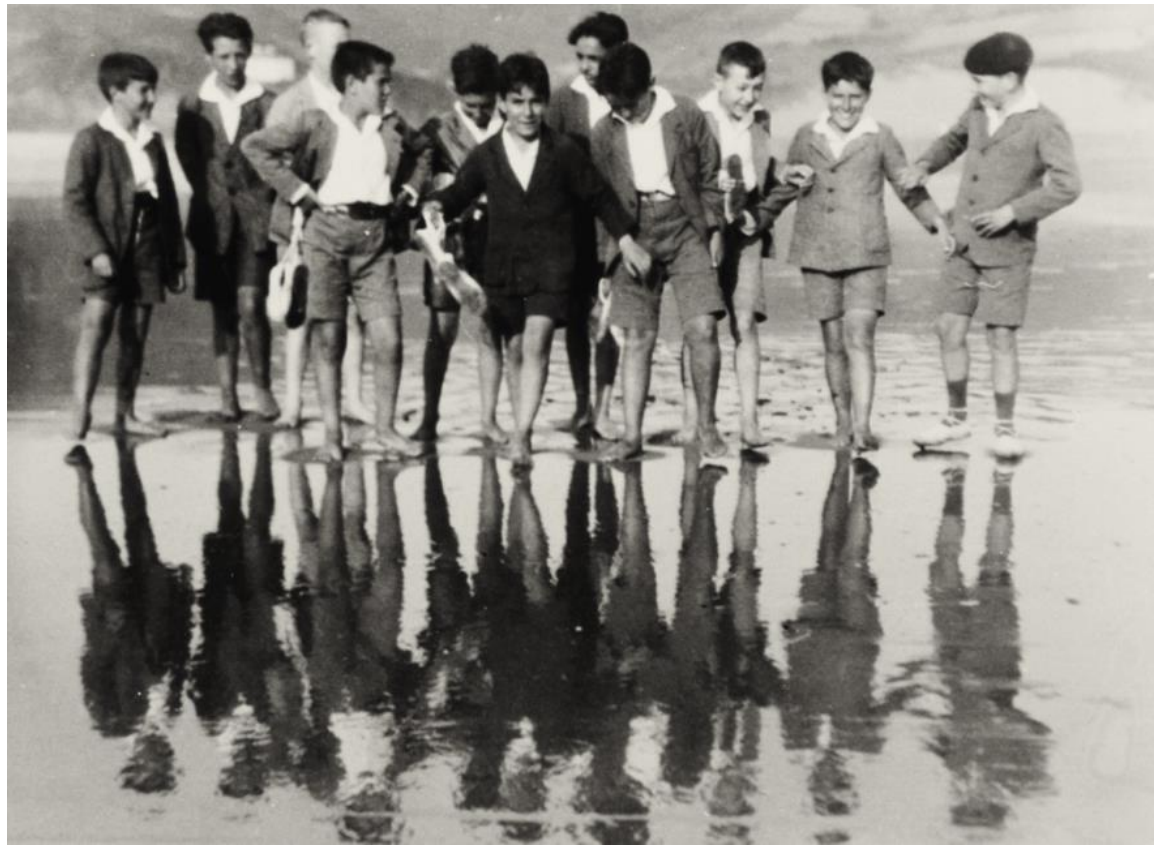

Fig. 2. Antonio de Guezala, [Julio Guezala y sus amigos en la playa de Bakio], c. 1925, Museo de Bellas Artes de Bilbao 
A esta ambivalencia, poco acorde con el afán clasificatorio de la historia del arte, se debe sumar la condición de la fotografía como una técnica mecánica que ha comportado una resistencia a ser aceptada como una actividad creativa, premisa indispensable para que fuera considerada como artística. Al mismo tiempo, su capacidad de registro de la realidad la alejaron, en un principio, de ser entendida dentro de unas nociones estéticas ${ }^{7}$.

Si bien podemos encontrar a autores que desde temprano supieron aplicar las posibilidades de un lenguaje propiamente fotográfico, este medio se ha topado continuamente con el obstáculo de querer ser entendida desde los parámetros de otras disciplinas artísticas, especialmente entendidos los de la pintura, provocando una suerte de complejo de inferioridad que no permitía su pleno desarrollo. Igualmente, esta subordinación, que en ocasiones parece no estar completamente superada, no hace más que negar las posibilidades expresivas, y desdeñar algunos de sus rasgos propios del medio, como su inherente carácter documental y sureproductividad.

Esta última es otra de las problemáticas intrínseca en la conjugación entre las bellas artes y la fotografía, al anular el concepto de unicidad, al que tradicionalmente se ha vinculado el aura de las obras de arte. Dejando de lado el aura, que bien podría ser objeto de un estudio en sí mismo, el concepto de exclusividad, a falta de unicidad, sigue prevaleciendo a la hora de valorar un objeto artístico. Muestra de ello es la práctica de seriar la fotografía, impuesta por el mercado del arte, con claros fines comerciales, en un absurdo de querer desposeerla de su capacidad de reproducción ${ }^{8}$. Estas reservas en asumir la reproductividad de la fotografía influyeron negativamente en la recepción de la fotografía por parte de las instituciones museísticas.

A pesar de estas reticencias, la fotografía tuvo una estrecha relación con el mundo del arte desde su nacimiento. De hecho, Nicéphore Niepce inició sus investi-

\footnotetext{
$7 \quad$ La idea de que una fotografía pudiera contener valores estéticos por sí misma, no empezó a difundirse en Europa hasta la década de 1880 .

8 El concepto de tiraje que se ha aplicado a la fotografía viene del grabado, técnica en la que tiene un sentido, ya que las planchas se deterioran. Por contra, el cliché fotográfico o el archivo digital son infinitamente reproducible y parece ilógico no aprovechar esa capacidad, que es el origen mismo de la técnica. Esta idea de numerar las fotografías viene dada por una pretensión de aumentar el valor del objeto fotográfico artificialmente.
} 
gaciones fotográficas con el fin de poder contar con un mecanismo que fuera capaz de reproducir obras de arte, pero también que solventara su falta de destreza en el dibujo. Por tanto, encontramos ya esa doble vertiente entre la practicidad de la reproducción y los anhelos creativos.

Fue la función de registro la que conllevó una primera aproximación de la fotografía al mundo del arte y a los museos, siendo desde temprano un instrumento fundamental en la difusión, investigación y catalogación de obras de arte.

Así, William Henry Fox Talbot, inventor del calotipo, en su libro The Pencil of Nature ya destacaba el papel de la fotografía como documento y fuente de conocimiento, ofreciendo varios ejemplos de reproducciones de obras de arte ${ }^{9}$. El mismo Talbot fotografió numerosos objetos artísticos, como las tablillas del British Museum, que hizo servir para sus propias investigaciones sobre la escritura cuneiforme, y fue él quien instó al Museo británico a emplear el medio para la documentación de sus obras y de sus actividades arqueológicas; iniciativa que el Museo adoptó a finales de la década de $1850^{10}$.

Igualmente, en Francia, el Museo del Louvre comienza en 1855 a fotografiar sistemáticamente su colección de esculturas, con vistas a la creación de un catálogo. También la Administración francesa promocionó proyectos para documentar las obras de arte estatales, como La Mission héliographique, creada en 1851 por la Administración Francesa de Bellas Artes para el registro de los monumentos históricos del país.

En España, dos de los principales fotógrafos del siglo XIX, Jean Laurent y Charles Clifford, llevaron a cabo una ingente labor de registro fotográfico de obras de arte, aunque el primero de ellos con una finalidad de comercialización. La empresa J. Laurent \& Cía reprodujo innumerables objetos artísticos y monumentos, así como

\footnotetext{
9 The Pencil of Nature fue publicado en seis volúmenes, de 1844 a 1846, por Longman, Brown, Green \& Longmans de Londres. La publicación contenía 24 calotipos originales y se considera el primer libro ilustrado con fotografías.

10 A pesar de la importancia que Talbot concedía a la fotografía para el conocimiento científico de distintas disciplinas, también defendió la capacidad expresiva de la misma. BRUSIUS, M., "William Henry Fox Talbot and the Variety of the Photographic Archive: Exploring Oxford's Photography Collections", History of Art at Oxford University: a blog about History of Art \& visual issues, 19 de diciembre 2014. [29/11/16]. Disponible en: https://oxfordarthist.wordpress. com/category/history-of-photography-2/
} 
varias colecciones de iglesias y museos, incluido el Museo de Prado, teniendo su exclusividad de 1879 a $1890^{11}$. Clifford, junto a su mujer Jane, llevaron a cabo el registro de las piezas del Tesoro del Delfín, adquiridas por el South Kensington Museum, y de la Real Armería ${ }^{12}$.

Estos primeros contactos de la fotografía con las instituciones artísticas tuvieron una finalidad funcional, pero quizás ese acercamiento al arte también tuviera algo de anhelo del medio por expresarse por sí mismo.

\section{Hacia una conciencia de la conservación fotográfica}

En cuanto a las instituciones y los organismos que se ocuparon de la conservación de la fotografía, durante el siglo XIX y buena parte del XX, no hubo entidades que gestionaran el Patrimonio fotográfico de forma específica. Se consideraba más como un documento gráfico, cuya importancia radicaba en la imagen que transmitía y no en el objeto en sí, por lo que su preservación era secundaria. Tampoco las agrupaciones fotográficas, que fueron la principal órbita de actuación de los fotógrafos desde finales del siglo XIX hasta prácticamente la década de 1980, tuvieron como objetivo la conservación del medio, aunque fueron creando sus propias colecciones a partir de la obra de sus socios u otros autores que participaban en concursos y actividades.

Así, la fotografía era conservada, generalmente, en los entes que la generaban, bien el propio estudio del autor, bien las entidades que habían encargado la producción o los particulares que habían adquirido copias, y así siguió siendo durante gran parte del siglo XX. Afortunadamente, con el paso del tiempo se van dando cada vez más excepciones a esta generalización, siendo los archivos públicos los que, con mayor frecuencia, se han ocupado de esta tarea ${ }^{13}$.

\footnotetext{
11 Además, J. Laurent \& Cía desarrolló el único ejemplo de grafoscopio que se conoce, un mecanismo rotatorio, con el que se visualiza una panorámica continua de la Galería Central del Museo del Prado, compuesta por 72 tomas, fue realizado en 1882 y 1883 .

12 SÁNCHEZ VIGIL, J. M. (coord.), La fotografia en España: de los origenes al siglo XXI, «Summa Artis. Historia general del arte», vol. XLVII, Espasa Calpe, Madrid, 2001, pp. 108-109.

13 El Arxiu Fotogràfic de Barcelona es uno de los pioneros, creado en 1931 como sección del Arxiu Històric de la Ciutat, siendo hoy en día uno de los principales del Estado por la riqueza de su contenido. En el ámbito vasco, el Archivo Municipal de Vitoria fue uno de los primeros en crear de un archivo específico de fotografía, en 1954.
} 
Mientras tanto, la introducción de la fotografía en las instituciones museísticas como pieza a conservar ha estado supeditada tanto a la superación de la noción tradicional de las Bellas Artes, como a la elevación de la fotografía al estatus de obra de arte. Las comentadas disquisiciones sobre la naturaleza de la fotografía, fueron superadas, en primera instancia, por determinados ámbitos artísticos, que significaron una sintomática de su aproximación del medio a la categoría dearte.

Se debe mencionar el caso del Museum of Modern Arte de Nueva York (MOMA), considerado como el primer museo que creó una sección específica de fotografía, en 1930, un año después de su apertura. Si bien se trata de una excepción, contextualizada, además, en uno de los países que más atención ha prestado a la fotografía, como es Estados Unidos.

Dejando de lado las excepciones, con el paso de los años la fotografía va tomando posiciones y acercándose a los circuitos del arte, siendo aceptada cada vez más como forma de expresión creativa. Sin embargo, hay que esperar hasta la década de 1970 para que la fotografía pase a formar parte, todavía de forma progresiva pero ya definitiva, de las colecciones y las actividades de los museos y los centros de arte, al menos en el ámbito europeo y estadounidense ${ }^{14}$.

En el caso de España, el conservadurismo cultural hizo que el reconocimiento de la fotografía fuera postergado. Pese a ello, durante la década de los setenta se dio una confluencia de iniciativas imprescindibles para dar visibilidad y poner en valor a la fotografía dentro de la cultura y de la sociedad, frente a la relativa marginalidad en la que se había mantenido anteriormente. Uno de los puntos fundamentales en este proceso fue la investigación y la recuperación histórica de la fotografía española, cuyos esfuerzos empezaron a dar sus frutos en la década de 1980. Todo ello incidió en una mayor concienciación sobre la necesidad de dar cabida a la fotografía dentro de los mecanismos de gestión patrimonial y, a su vez, en su acogimiento en el seno de los museos.

14 PÉREZ GALLARDO, H., y VEGA, C., "Arte y fotografía (III): La fotografía en el museo: entre el objeto documental y artístico", SOUGEZ, M. L., Historia general de la fotografia, «Manuales arte Cátedra», Cátedra, Madrid, 2009, pp. 570-588. 
En este contexto, se llevan a cabo las primeras iniciativas para la conservación de la fotografía, con la creación de entes privados que recogían este aspecto entre sus objetivos ${ }^{15}$. Es el caso del Institut d'Estudis Fotogràfics de Catalunya, creado en 1972, que en la actualidad custodia un valioso archivo de fotografía; o el Centre Internacional de Fotografia, en 1978, que abarcaba un amplio espectro de actividades en torno a la formación, la difusión y la preservación del medio ${ }^{16}$. No obstante, se trata de dos excepciones, ya que no es hasta los años noventa que se da un interés generalizado por estas cuestiones a nivel estatal. Esta revalorización también se aprecia en el surgimiento de fotogalerías, que tuvieron un auge en los años ochenta, creando un incipiente mercado, si bien sufrieron un retroceso en la década siguiente.

En cualquier caso, el impulso que había tomado la fotografía, tanto en el ámbito comercial como en su divulgación, ya no tenía marcha atrás; asentándose las bases para que el medio disfrutara de su propio espacio en la vida cultural y en la sociedad. Este mismo empuje tuvo una repercusión en las instituciones y los organismos públicos, especialmente en aquellos entes dedicados a la conservación y difusión del patrimonio cultural, donde la fotografía fue introduciéndose gradualmente.

Las primeras instituciones museísticas en atender las demandas de la fotografía lo hicieron en la década de 1980, aunque la presencia de la fotografía en los museos no se generaliza hasta prácticamente finales de los años noventa, y aun con reticencias, siendo pocas las instituciones que plantean una política activa al respecto.

Cabe mencionar también, como un hecho significativo en el reconocimiento de la fotografía en su vertiente creativa, su entrada en la Academia de Bellas Artes de San Fernando. En 1989 se crea la sección de Artes de la Imagen, y Alfonso Sánchez

\footnotetext{
15 A nivel internacional dos referentes en la preservación fotográfica son Image Permanence Institute, fundado en 1985 (en el Plan Nacional de Conservación de Patrimonio Fotográfico se data la fundación en 1978), al amparo del Rochester Institute of Technology, EEUU, y Atellier de restauration et de conservation des photographies de la Ville de Paris, en 1983. Los primeros manuales de conservación se publican a principios de la década de los ochenta, cuando también se dan los primeros eventos internacionales dedicados a esta materia. Se ofrecen datos concretos sobre estos y sobre la evolución de la conservación fotográfica en España en: Plan Nacional de Conservación del Patrimonio Fotográfico, op. cit., pp. 14-20.

16 Aunque fuera posterior, cabe citar por el alcance de su labor, el Centre de Recerca i Difusió de la Imatge de Girona, creado en 1997, cuyos predecesores venían organizando las Jornades Imatge i Recerca en torno a la fotografía desde 1990.
} 
Portela es elegido como el primer académico fotógrafo, en 1989. Sánchez falleció antes de leer el discurso de ingreso y su vacante fue cubierta por Juan Gyenes, en 1991, quien además era miembro de la Academia de Bellas Artes de San Telmo de Málaga desde hacía tres años. Los otros autores o historiadores del entorno de la fotogra- fía seleccionados como académicos han sido: Alberto Schommer, en 1996; Publio López Mondéjar, en 2008, y Cristina García Rodero, en 2013. Además, la Academia de Bellas Artes ha abierto a principios del 2019 una sala exclusiva de fotografía, reconociendo con ello su papel en el panorama artístico actual.

\section{La fotografía en los museos españoles}

Anterior al contexto que venimos comentando, como un caso excepcional, hay que mencionar al Museo Municipal de Madrid, cuyo fondo fotográfico fue creado en 1926, siendo ampliado considerablemente con el paso de los años.

Volviendo al contexto de reivindicación de la fotografía de la Transición, el Museo Nacional Centro de Arte Reina Sofía (MNCARS) fue el primero en emprender una política específica en su gestión ${ }^{17}$. La presencia esporádica de obra fotográfica en el anterior Museo Español de Arte Contemporáneo se puede rastrear desde 1923, cuando tienen lugar una exposición dedicada a Pedro Cano Barranco. El Museo Español de Arte Moderno también acogió los Salones Internacionales de Fotografía de Madrid, organizados por la Real Sociedad Fotográfica de Madrid, en su edición VII y IX, en 1928 y 1932, respectivamente. Tras la Guerra Civil, una de las primeras exposiciones de fotografía que acoge el Museo de Arte Contemporáneo es la de Arenas Ladislao, en 1946. Posteriormente, en 1953, se exhibirán fotografías de Carlos Saura, y en 1960 de Juan Gyenes.

En cuanto a la gestión de la fotografía interna, en 1984 se instituye un primer Dpto. de Foto Video y Artes de la Imagen, al que pasan a formar parte obras

\footnotetext{
17 El Museo Nacional de Arte Moderno pasa a integrar, en 1971, el Museo Español de Arte Contemporáneo que pasa a ser el Museo Nacional Centro de Arte Reina Sofía, inaugurado en 1992.
} 
fotográficas con las que ya contaba la colección del MNCARS ${ }^{18}$. Otro hecho relevante es la organización de las Jornadas para la conservación y recuperación de la fotografia, en 1985, bajo el auspicio del Ministerio de Cultura, así como de una serie de adquisiciones de relevancia para la Colección de fotografía durante los años siguientes.

Otro de los centros que ha abanderado la inserción de la fotografía en los museos españoles es el Institut Valencià d'Art Modern (IVAM, 1986). Desde su inauguración contaba ya con depósitos y donaciones de fondos fotográficos, entre los que se cuentan la colección de la Real Academia de San Carlos de Valencia, la de Ordónez-Falcón, la de Gabriel Cualladó o la de la Fundación Josep Renau. A partir de estos fondos se fue ampliando y su campo de acción con otras donaciones y adquisiciones hasta conformar un conjunto de gran interés dentro de la Historia de la Fotografía. También su programación expositiva mantuvo esta apuesta por el medio.

Por su parte, la Fundació Joan Miró, en Barcelona, presentó exposiciones fotográficas a partir de 1979; un año más tarde, acoge las I Jornadas Catalanas de Fotografia, y fue una de las impulsoras de la primera edición de la Primavera Fotográfica en 1982. También creó un departamento fotográfico con el fin de apuntalar su colección, iniciada con donaciones, que además sería un centro de investigación, de actividades y edición de portfolios, aunque, finalmente, no prosperó.

El empuje de la fotografía durante estos años también se advierte en el surgimiento de centros públicos dedicados a la fotografía, algunos para su difusión como La Virreina de Barcelona, de 1980. Otros centrados en la recuperación e investigación, como el Centro de Estudios Fotográficos de Vigo, de 1985, que no tuvo continuidad; el Centro Galego de Artes da Image, en A Coruña, y el Centro de Fotografía de la Isla de Tenerife, ambos creados en $1989^{19}$.

A pesar de este incipiente interés y esta primera aceptación de la fotografía en los museos, su consolidación, como parte de las políticas de colecciones, tendrá

\footnotetext{
18 En 1984 todavía era el MEAC. Este departamento no llegó a consolidarse, siendo en 1995 cuando se crea, definitivamente, un departamento específico de fotografía, dirigido por Catherine Coleman.

19 Otras iniciativas posteriores de instituciones dedicadas de forma exclusiva a la fotografía son el Centro Andaluz de Fotografía (1992) y, en el ámbito privado, el Photomuseum de Zarautz (1993)
} 
que esperar hasta mediados e incluso finales de la década de $1990^{20}$. Al respecto, la creación de varios museos dedicados específicamente al arte contemporáneo, en la línea del IVAM, propició la introducción de la fotografía como objeto museable ${ }^{21}$.

Dentro de este panorama, la ausencia de un área de conocimiento específico de fotografía dentro de la Universidad, inevitablemente se traducía en una carencia formativa y de tradición investigadora ${ }^{22}$. Esta circunstancia ha propiciado que la aceptación de la fotografía dentro de los museos se produjera sin una plena concienciación sobre sus necesidades específicas. Más aún cuando muchas de estas cuestiones tampoco estaban definidas, careciendo de una bibliografía teórica sobre su gestión, al menos en castellano. De hecho, muchos museos ya contaban con fotografías en sus colecciones, principalmente como parte de fondos de artistas e intelectuales o de sus archivos, pero habían sido tratadas con una cierta indiferencia ${ }^{23}$.

Con el paso de los años, la concienciación hacia la fotografía dentro de los museos ha ido en aumento, y se han establecido pautas de trabajo y metodologías específicas, si bien no hay unanimidad ni acuerdo sobre su tratamiento, al igual que sucede, en buena medida, a nivel internacional. Como se ha mencionado, con el fin de solventar esta situación, se redactó el Plan Nacional de Conservación del Patrimonio Fotográfico. También la aplicación informática DO- MUS, desarrollada por el Ministerio de Cultura para la documentación y gestión museográfica, y aplicada progresivamente a partir del 2001, tiene como objetivo la normalización

\footnotetext{
20 El Museu Nacional d'Art de Catalunya es otro de los museos referentes en la consolidación de una política fotográfica específica, con la creación de un departamento de fotografía a mediados de los noventa.

21 También se pueden citar el MACBA en Barcelona, MEIAC en Cáceres, el CAAM en Las Palmas de Gran Canaria o el CGAC en Santiago. Sobre la presencia de la fotografía en los museos y otras instituciones consultar J.M. SÁNCHEZ VIGIL, El documento fotográfico: historia, usos, aplicaciones, «Biblioteconomía y administración cultural, 140», Ediciones Trea, Gijón, D.L. 2006; J. M. SÁNCHEZ VIGIL, La fotografia en España: otra vuelta de tuerca, «Bibliotecono- mía y administración cultural, 261», Ediciones Trea, Gijón, 2013; y C. VEGA, Fotografia en España (1839-2015): historia, tendencias, estéticas, Cátedra, Madrid, 2017.

22 Este vacío se ha atenuado con títulos ofertados por algunas universidades, como la Universitat Autònoma de Barcelona o la Universitat Politècnica de València, entre otras, si bien la fotografía no tiene una presencia normalizada y estable, como sucede con otros campos del saber. Asimismo, desde el Plan Nacional de Conservación del Patrimonio Fotográfico se apuesta por la inclusión de nociones fotográficas en distintos niveles formativos, desde la Educación Secundaria.

23 A raíz de esta mayor preocupación por los fondos fotográficos, se hizo una recuperación de las colecciones de fotografía, recogida en: La fotografia y el museo, Dirección General de Bellas Artes y Bienes Culturales, [Madrid], D.L. 1997. Patrimonio Nacional hizo lo propio a través de una exposición de la publicación: La fotografia en las colecciones reales, Patrimonio Nacional; Fundación La Caixa, [Madrid], D.L. 1999.
} 
de terminologías y la unificación de los elementos descriptivos y clasificatorios, aunque no cuenta con el consenso de las redes de museos en el Estado, siendo significativa la ausencia de los museos catalanes y vascos en su aplicación.

Igualmente, cabe señalar la creación de EMSIME, como base de datos común a los museos del País Vasco ${ }^{24}$. Esta plataforma está ideada para adaptarse a instituciones museísticas con distintas particularidades, con entradas específicas dedicadas a la obra fotográfica, que facilitan la aplicación de una terminología especializada.

Precisamente, las mismas cuestiones que supusieron un rechazo de la fotografía por parte de la crítica artística y de las instituciones museísticas son, hoy en día, las que provocan un cierto desajuste en su gestión y tratamiento dentro de las distintas entidades que se ocupan de la preservación de obra fotográfica, y especialmente en los Museos. Así, tanto su reproductividad como la multiplicidad de sus funciones y materiales provocan unas fricciones en la adecuación a las formas de gestión de las instituciones, a lo que añadir su presencia en archivos, bibliotecas y museos, entre otros organismos, que se rigen por distintos protocolos de actuación. Todo ello repercute en la dificultad para establecer unas pautas fijas en la catalogación y descripción del material fotográficos.

\section{La Colección de Fotografía del Museo de Bellas Artes de Bilbao: forma- ción y características de un conjunto heterogéneo}

Para entender la pertinencia y el lugar que ocupa la Colección deFotografía es imprescindible contextualizarla y vincular las peculiaridades de su formación dentro del Museo de Bellas Artes de Bilbao, institución esta.

El actual Museo de Bellas Artes de Bilbao es fruto de la fusión de un primer Museo de Bellas Artes, que se inauguró en 1914, y del Museo de Arte Moderno de Bilbao, inaugurado en 1924. Ambos museos se gestionan de forma conjunta a partir

24 El Museo de Bellas Artes de Bilbao la implantó a partir del 2014. Euskadi.eus: Patrimonio cultural: EMSIME. [15/02/16]. Disponible en: https://apps.euskadi.eus/emsime/catalogo-museos-pais-vasco/ 
de 1945, cuando comparten las mismas instalaciones y director. Si bien no es hasta 1970 que ambos se funden en una misma institución de forma oficial25.

Este origen tiene que ver con el carácter de la institución actual que, pese a su denominación, difiere de la praxis habitual de un museo de Bellas Artes al uso, especialmente respecto al espacio que ocupa el arte contemporáneo, tanto en su programación como en sus colecciones. Se trata de una herencia directa de las reivindicaciones específicas por las que fue creado el Museo de Arte Moderno, que pretendía ocuparse de aquellas manifestaciones más contemporáneas de cada momento. Esta cuestión también incide, directamente, en la presencia de obra fotográfica en el Museo y en el papel jugado por la institución como avanzada difusora de dicho medio.

Igualmente, se debe ubicar la Colección de Fotografía del Museo como parte de un conjunto, mucho más amplio, de colecciones del Museo, que abarcan cronológica y territorialmente un vasto marco de representación de la actividad artística. La misma fotografía forma parte de esa heterogeneidad de estilos y disciplinas que caracteriza a la totalidad de las colecciones del Museo.

\section{Las exposiciones de obra fotográfica en el Museo de Bellas Artes de Bilbao}

Apartir del año 1980, y hasta mediados de los noventa, cuando la fotografía adquiere una relevancia notable en la actividad del Museo. Esdurante ese período la institución lleva a cabo una notable difusión de la fotografía, a través de una intensa programación de exposiciones, que se encaminaba a su plena aceptación como lenguaje vehicular de la acción creativa. Esta labor se inserta dentro de una política activa en la puesta en valor del medio, en consonancia con las instituciones más aventajadas del panorama estatal.

Así, desde 1980 hasta 1983 se organizan cuatro exposiciones anuales de obra fotográfica, siendo la primera la del fotógrafo bilbaíno Pedro Zarrabeitia ${ }^{26}$.

\footnotetext{
25 M. ZUGAZA MIRANDA, "Pasado y presente del Museo de Bellas Artes de Bilbao", Maestros Antiguos y Modernos: Museo de Bellas Artes de Bilbao, Fundación BBK Fundazioa, Bilbao, 1999, pp. 15-29.

26 En 1953 el Museo de Bilbao acoge su primera exposición de fotografía, Fotografías de arquitectura contemporánea
} 
Tras esta tímida presentación, se da una etapa en que la difusión del medio ocupa un espacio constante en el calendario expositivo del Museo, pasando a contarse entre cuatro y seis exposiciones anuales dedicadas a la fotografía. Entre ellas, tienen cabida desde los fotógrafos históricos hasta otros en activo, de distintos ámbitos territoriales. En su conjunto, las exposiciones presentadas durante dicha década y buena parte de la siguiente, ofrecen a la sociedad vizcaína una encomiable introducción al conocimiento de la Historia de la Fotografía, que bien podría ponerse en parangón con la programación de instituciones actuales.

Las exhibiciones de fotografía internacional, entre las que predominaron las de carácter histórico, eran muestras itinerantes organizadas por otros organismos. Entre ellas encontramos las dedicadas a los maestros fotógrafos del siglo XIX, como Henry Peach Robinson en 1989, Nadar en 1992 y William Henry Fox Talbot en 1993. También aquellos fotógrafos que iniciaron su actividad en la primera mitad del siglo XX y la desarrollaron durante buena parte del mismo, como Manuel Álvarez Bravo en 1985, François Kollar en 1991, Martín Chambi en 1992, Robert Capa en 1992 y August Sander en 1993. También exposiciones dedicadas a movimientos de vanguardia, como Fotografia futurista italiana 1984 y Fotografía en la época de Weimar en 1994. Acercándonos a generaciones más jóvenes, sobresalen las muestras de Manuel Álvarez Bravo en 1985, Joel-Peter Witkin en 1988, Graciela Iturbide en 1992 y John Davies en 199427. También tendrán su espacio los artistas menos consagrados, con dos muestras colectivas dedicadas a la fotografía actual, una de Quebec y otra de Japón, ambas en 1986.

Igualmente, en su programación aparecen algunos de los proyectos expositivos de la época, que son fruto de los inicios de la investigación y recuperación de la fotografía española. Entre ellos destacamos dos cuyos catálogos siguen siendo publicaciones de referencia en el estudio de la Historia de la Fotografía Españolas. Se trata de Idas y caos. Aspectos de las vanguardias fotográficas en España, expuesta en 1985; Las fuentes de la memoria, en 1990, y Cuatro, en 1993.

\footnotetext{
americana; una exposición itinerante organizada por la Casa Americana en Bilbao y el Colegio de Arquitectos Vasco-Navarro, siendo este un hecho excepcional.

27 John Davies participa en el proyecto Bilbao, ría de hierro, un año antes, cuya producción resultante se conserva en el Museo de Bellas Artes de Bilbao. La exposición individual tuvo como título Tendencias Cruzadas.
} 


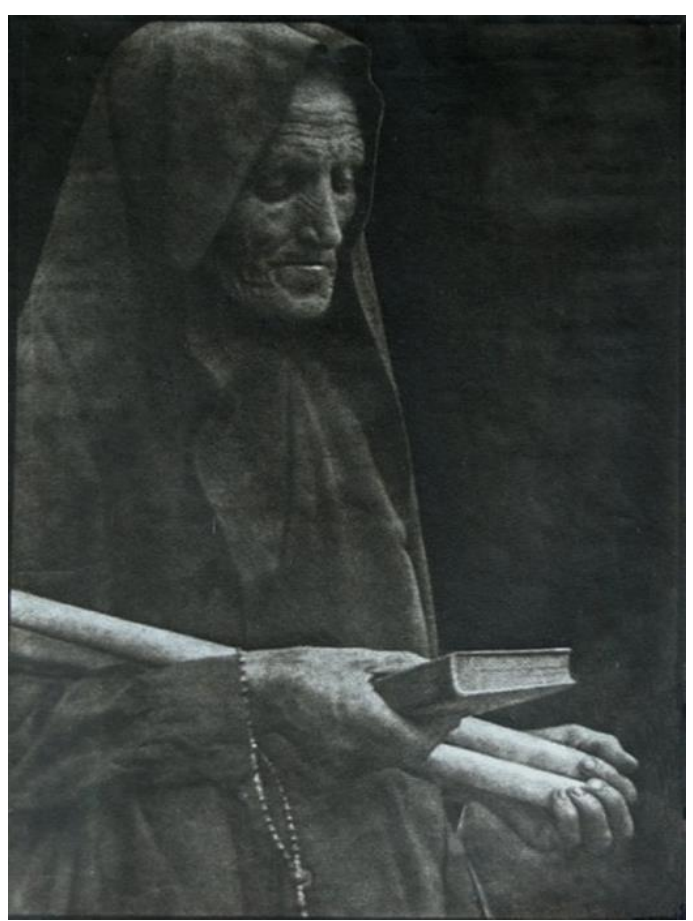

Fig. 3. Tomás de Acillona, Día de difuntos, c. 1947-1948, Museo de Bellas Artes de Bilbao

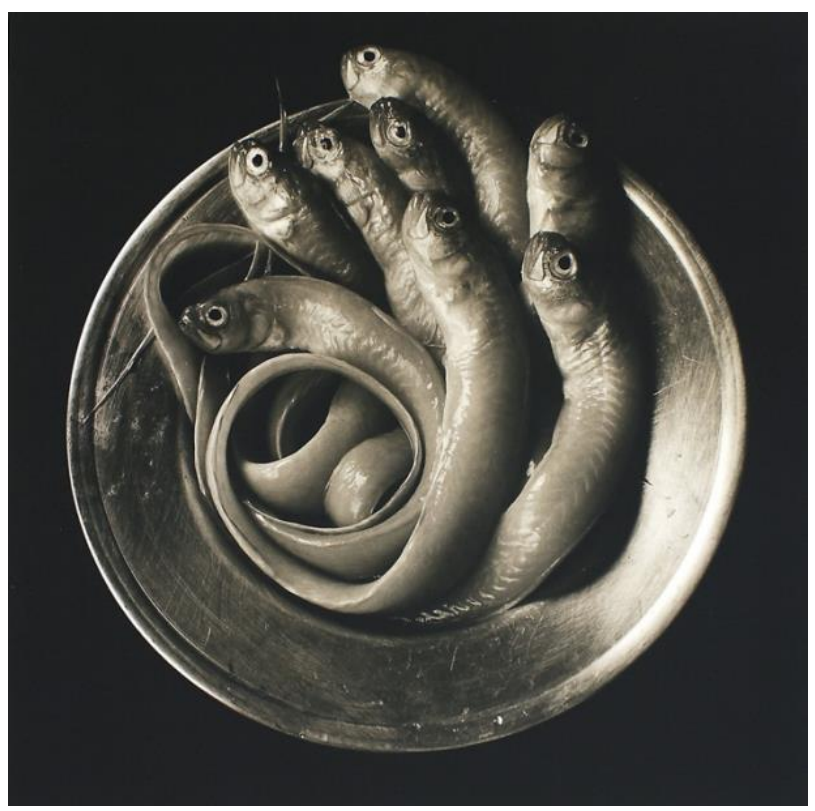

Fig. 4. Josep Maria Ribas i Prous, Els peixos, 1982, Museo de Bellas Artes de Bilbao 
La escasez de muestras de fotógrafos españoles anteriores a los años cincuenta debe relacionarse con el hecho de que, en buena medida, todavía se estaban llevando a cabo las primeras tareas de localización y estudio de muchos de los fondos y archivos de fotógrafos. Pese a ello, sí encontramos la muestra Dalífotógrafo en 1984, y un año más tarde otra sobre fotografías de Ramón y Cajal.

Entre los fotógrafos españoles más recientes, destacan aquellos que contaban con una trayectoria consolidada, desarrollada durante la segunda mitad de la centuria, pero a los que aún no se les debía reconocido como merecían. Así sucede con Josep Maria Ribas i Prous, que expone en 1984, Gabriel Cualladó en 1985 y Francesc Català-Roca en 1986.

Pasando a una generación posterior, se dieron muestras de los jóvenes fotógrafos que en muchos casos fueron los impulsores de las iniciativas para la revalorización del medio fotográfico, pudiendo citar las de Joan Fontcuberta en 1986, Rafael Navarro en 1987, y Tony Catany en 1994.

En las muestras del ámbito regional se mantiene esa doble tendencia a la recuperación de fotógrafos del pasado, como Nicolás de Lecuona, expuesto en 1982 y Felipe Manterola en 1983, junto a la difusión de la obra de autores en plena actividad, como la citada de Pedro Zarrabeitia en 1980, o Alberto Schommer en 1987, de quien también se organiza una antológica en 2010. Además de la de Juantxu Rodríguez, en 1991, dos años después de ser asesinado ${ }^{28}$.

En el último lustro del siglo XX, se aprecia un descenso en la presencia de fotografía en las salas del Museo de Bilbao; precisamente, cuando la fotografía toma mayor protagonismo en los circuitos artísticos del resto de España. Posteriormente, se dan dos muestras dedicadas a la colección de fotografía Ordoñez-Falcón en 2008 y 2009, en las que el Museo de Bilbao colaboró en su producción, pasando además a conservar una parte de las piezas en calidad de depósito ${ }^{29}$. En 2010, se dan las dos úl-

\footnotetext{
28 Juantxu Rodríguez fue el primer fotorreportero español asesinado en acto de servicio, en Panamá.

29 El Museo de Bellas Artes de Bilbao conserva en calidad de depósito la colección Ordoñez-Falcón que corresponde a la fotografía histórica, mientras que la sección de fotografía contemporánea de esa misma colección fue cedida, inicialmente, al IVAM de Valencia y, posteriormente, trasladada al Fondo de Fotografía Isla de Tenerife, en el Tenerife Espacio de las Artes (TEA), donde se custodia actualmente. Igualmente, custodia como depósito obra de Alberto
} 
timas exposiciones de producción propia del Museo de Bellas Artes de Bilbao, dedicadas a Tomas de Acillona y a Alberto Schommer, respectivamente. Las dos últimas que ha acogido el Museo, fueron itinerantes, siendo dos muestras de primer orden a nivel internacional: New Topographics en 2011-1012 y La maleta mexicana en 2012.

Como complemento a la actividad expositiva, en los casos en los que el Museo participó en la organización, la difusión de las obras exhibidas se reforzó con la publicación de catálogos, con la única excepción de la exposición de Ribas i Prous, que contó con un escueto tríptico. Destaca, entre ellos, el de Gabriel Cualladó, que se articula como un estudio de la obra del autor ${ }^{30}$. Además, estas exhibiciones coinciden mayoritariamente con donaciones de obra. Ya en el siglo XXI, destacan los catálogos de las cuatro exposiciones citadas en las que participa el Museo, con publicaciones que dan un salto cualitativo notable respecto a las de los años ochenta y noventa.

Aunque sólo se han mencionado algunas de las muestras fotográficas que han tenido lugar en el Museo, la relación completa de las que se dieron, especialmente desde 1980 hasta 1997, traza unas firmes pinceladas sobre el discurrir histórico del medio, a modo de discurso sintético, mostrando algunos de los vericuetos por los que ha transitado la fotografía ${ }^{31}$. Pero, además, los datos publicados sobre algunas de las instituciones españolas más destacadas, hacen pensar que en algunos casos se trata de las prime- ras muestras de los autores dentro de nuestras fronteras. Así se aprecia si comparamos con el MNCARS, donde Robert Capa se expone en 1999; Manuel Álvarez Bravo en 1996; Man Ray en 1999, y la fotografía de Nicolás de Lecuona en $2004^{32}$.

\footnotetext{
Schommer, además de la que sí forma parte de sus colecciones.

30 En paralelo al catálogo de la exposición en el Museo de Bilbao, editado por Caja de Ahorros Vizcaína, la Dirección General de Bellas Artes y Archivos publicó otro con el mismo contenido con motivo de la exhibición misma en el Museo Español de Arte Contemporáneo. Esta muestra fue la segunda de carácter retrospectivo de la obra del autor.

31 El listado completo de exposiciones fotográficas en el Museo de Bellas Artes de Bilbao hasta 2014 se lista en el Apéndice 1 de la Tesis doctoral D. FABRA ANTON, La Colección de Fotografia del Museo de Bellas Artes de Bilbao (19142014): estudio, catalogación y análisis. Dirigida por José Manuel Susperregui y Concha Casajús, Universidad Complutense de Madrid, 20 de febrero 2019.

32 Los datos sobre las exposiciones del MNCARS han sido extraídos de C. VEGA, Fotografia en Espana (18392015): historia, tendencias, estéticas, Cátedra, Madrid, 2017.
} 


\section{La creación de la Colección de Fotografía del Museo de Bellas Artes de Bilbao}

Pese a no existir una equivalencia entre la política expositiva y la conformación de los fondos del Museo, ambas forman parte de un mismo proyecto de reivindicación del medio fotográfico y su conservación.

$\mathrm{Al}$ respecto, un hecho destacado a mencionar es la creación de un Gabinete fotográfico por parte del Museo en 1983, a modo de departamento especializado que se dedicaría a la recuperación, preservación y a la difusión del medio. El gabinete sería asesorado por Ramón Serras, Pedro Zarrabeitia e Iñaki Markaida. Se trata de uno de los primeros casos que se dan en nuestro país, que se adelanta por un año al Museo Español de Arte Contemporáneo, en 1984, y la Fundació Joan Miró en 1985. La propuesta no llegó a consolidarse, como tampoco sucedió en los otros dos casos, sin embargo, evidencia el firme propósito de plantear una política de largo alcance dedicada a la fotografía, así como una preocupación hacia su preservación; una cuestión que hasta el momento no había sido objeto de atención por parte de las instituciones museísticas. Se debe añadir el hecho de tratarse de un Museo de Bellas Artes, cuyo arco cronológico abarca desde del siglo III a. C hasta la actualidad, mientras que los otros dos mencionados están dedicados al arte contemporáneo, lo que lo con- vierte en un caso excepcional.

Se debe citar a Leopoldo Zugaza, miembro de la Junta del Patronato del Museo en aquella etapa, como el principal impulsor de dicho esfuerzo por crear un espacio propio para la fotografía dentro de la institución, así como de la promoción de exposiciones y la creación de la Colección de Fotografía ${ }^{33}$.

La presencia de obra fotográfica en los fondos del Museo de Bellas Artes de Bilbao fue marginal hasta 1982. Hasta un año antes, se contaba únicamente con tres fotografías aisladas.

\footnotetext{
33 También es remarcable la labor en pro de la fotografía llevada a cabo en el seno del Museo por José Julián Bakedano, cineasta y especialista en el medioaudiovisual. En 1992, Leopoldo Zugaza emprendió, a título personal, la iniciativa de crear el primer museo en el Estado dedicado exclusivamente a la fotografía, el Photomuseum de Zarautz.
} 
Se trata de: Laureano de Jado a los 19 años y tres meses, del estudio Alonso Martínez y Hermano; [Retrato de niña], del estudio Lázaro de Régil, y Dario de Regoyos pintando en una calle de Durango, de Manuel Torcida. Las tres comparten la característica de haber entrado al Museo donadas como parte de importantes colecciones particulares, como la de Laureano de Jado, clave en la gestación del Museo, siendo, además la fotografía más antigua que se conserva, fechada en 1862, seguida por las otras dos, de finales del siglo XIX. Una cuarta obra que también forma parte de una colección multidisciplinar, es un retrato de estudio anónimo del coleccionista Diego Picaza y Garay, fechado hacia la década de 1930 y donado en 1985. Las cuatro obras tienen una función de recuerdo que responde a uno de los principales usos que ha tenido la fotografía profesional, el de efigiar a un personaje.

En 1982, las colecciones del Museo registran, por vez primera, fondos propiamente fotográficos. Se trata de dos conjuntos con obra de varios autores, Arteder' 82 y Cinco años de prensa gráfica, y uno individual, el de Josep Maria Ribas i Prous ${ }^{34}$. Este último, fue donado por el autor, comprende las obras enviadas para participar en la feria Arteder'82, junto a una carta del fotógrafo en la que ofrecía las obras al Museo generosamente. A partir de ese momento, en paralelo a la actividad expositiva, se lleva a cabo una política de ampliación de los fondos fotográficos, que durará hasta 1997.

El fondo Arteder'82 contiene tres obras ganadoras de la sección de fotografía de la Feria Internacional de Obra Gráfica, cedidas al Museo. Junto a estas, hay otras 95 fotografías que fueron enviadas a participar en la feria, pertenecientes a 30 autores, la mayoría de ellos miembros de la Lietuvos Fotografijos Meno Draugija (Sociedad Lituana de Arte Fotográfico). Entre ellos destacan algunas de las principales figuras de la fotografía lituana, tanto de la generación ya

\footnotetext{
34 El fondo Cinco años de prensa gráfica estaría en el Museo desde junio de 1981, cuando tiene lugar la muestra que lo origina. En 1982, el Museo de Bellas Artes de Bilbao lleva a cabo una ingente labor de catalogación de sus fondos, incluyendo aquellos cuyo ingreso no se había registrado, como éste.

35 Arteder'82: Muestra Internacional de Obra Gráfica: Sección: III Fotografia, Feria Internacional de Muestras de Bilbao, Bilbao, D.L. 1982, y M. RUFÍ-GIBERT, “Arteder'82 (Bilbao)”, Batik: panorama general de las artes, n. ${ }^{\circ}$ 67, año X, abril 1982, pp. 14-15.
} 
consolidada que se inició en la fotografía hacia la década de 1960, como Antanas Sutkus, Aleksandras Macijauskas, Stanislovas Žvirgždas y Vitalijus Butyrinas. Como otros más jóvenes, ya influenciados por el postestructuralismo, como Milda Drazdauskaitè, Vytautas Balčytis y Violeta Bubelytė, entre otros. Las obras se fechan hacia 1980-1982. El conjunto nos descubre un episodio de la Historia de la Fotografía de una gran singularidad, al tratarse de una agrupación perteneciente al estado, algo excepcional, y por fomentar la adopción de distintas formas expresivas de la fotografía. La temática de la llamada Escuela Lituana gira en torno a la cotidianidad y la conformación de un imaginario nacional, que se manifiesta en el retrato psicológico, el comportamiento humano y el paisaje36.

Tampoco se conserva documentación sobre la entrada del fondo Cinco años de prensa gráfica: País Vasco 1975-80, título de la segunda exposición de fotografía celebrada en el Museo en $1981^{37}$. Las fotografías que conserva el Museo fueron probablemente expuestas en la muestra y otras serían parte del material preparatorio. Se trata de 123 fotografías, de varios formatos, de siete autores profesionales del ámbito periodístico, entre los que destaca Arturo Delgado, con 78 obras, mientras que 16 son anónimas. El resto de autores son: Germán Elorza, Francisco Gras, Manu Cecilio, Cristóbal Fernández, Alfredo Aldai y Jaime ${ }^{38}$.

El tercer y último conjunto de fotografía perteneciente a varios autores es la colección Bilbao, ría de hierro de 1993, producida por encargo de la asociación Bilbao Metrópoli-30, como parte de un programa de promoción y documentación de las transformaciones urbanas, económicas y sociales de Bilbao, con una función propagandística.

\footnotetext{
36 Sobre la fotografía lituana: R. JURĖNAITĖ, Lietuvos fotografija: Vakar ir siandien = Lithuanian Photography: Yerterday and Today, Lietuvos fotomenininku sajungos fotografiju fondas, Vilnius, 2003, y V, MICHELKEVIĊIUS, The Lithuanian SSR Society of Art Photography (1969-1989): An Image Production Network, Vilnius Academy of Arts Press = Vilniaus dailès akademijo leidykla, [Vilnius], 2011.

37 Cinco años de prensa gráfica: País Vasco 1975-80, Museo de Bellas Artes de Bilbao, [Bilbao], 1981.

38 Este último autor no ha podido identificarse, siendo un sello en la trasera de su fotografía la única referencia encontrada. Tampoco en el archivo del Diario el Hierro, al que pertenecía la obra se localizó información sobre él.
} 
El proyecto, con un total de 86 obras, fue llevado a cabo por seis fotógrafos. Esta colección fue donada en 1997 por Bilbao Me- trópoli-30, acompañada de su correspondiente exposición en el Museo ${ }^{39}$.

Los fondos colectivos Arteder'82 y Bilbao, ría de hierro son los únicos con presencia de autores internacionales no residentes en España. Destaca especialmente el segundo por tratarse de fotógrafos con una carrera consolidada y por su calidad, como son Gabriele Basilico, John Davies, Bruce Gilden, Carlos de Andrés, Carlos Cánovas y John Vink. También el número de obras de cada autor, entre 14 y 15, le da una representatividad más consistente, mientras que en Arteder'82 se da una media de 5 obras por autor, con cifras muy desiguales en cadacaso.

Pasando a los fondos formados por obra de un solo autor, hay cuatro que se pueden denominar históricos, encuadrados cronológicamente desde finales del siglo XIX hasta mediados del siglo XX. Respecto a las donaciones de estos fondos, fueron propiciadas por una labor de recuperación del Patrimonio fotográfico regional, llevada a cabo por el Museo de Bilbao.

El primero de ellos es el fondo de Enrique Epalza, fechado a finales del siglo XIX, compuesto por 99 copias modernas, realizadas a partir de positivos al colodión, algunos de ellos pares estereoscópicos, con motivo de su exhibición en Bilbao a fines del siglo XIX, en $1985^{40}$. En dicha muestra las obras aparecieron como anónimas, siendo atribuidas al autor con posterioridad. Enrique Epalza (Bilbao, 1860-1933) fue arquitecto de profesión y un ávido aficionado a la fotografía. Consciente de la capacidad de la fotografía para configurar un ideario común, así como del papel de la arquitectura y el urbanismo para la proyección de unas ideas y valores, el autor construye su propio discurso visual sobre Bilbao. Epalza reformula la noción de la ciudad, que deja de ser una villa para mostrarse como capital industrial, en una visión ligada a la modernidad y el progreso, a través de las nuevas construcciones

39 Ría de Hierro = Burdinezko itsas-adarra = Iron River, Bilbao Metrópoli-30; Ediciones Laga, Bilbao, 1993.

40 Bilbao a fines del XIX, Museo de Bellas Artes de Bilbao, Bilbao, 1985. 
urbanas y de ingeniería. Su modernidad también se distingue en el repertorio que hace de los distintos estratos sociales de la Villa, sin distinciones o jerarquizaciones, así como en la documentación de sucesos y eventos, anticipando la figura del reportero gráfico. Su ideario visual, cercano al de la tarjeta postal, también está compuesto de retratos de tipos populares y escenas costumbristas, aunque en las imágenes de Epalza se distingue un lenguaje fotográfico menos convencional, con una especial atención a la concepción espacial, que es común a toda su obra.

Felipe Manterola (Zeanuri, Bizkaia, 1885-1977) es el autor de otro de los fondos. Su ingente producción fue dada a conocer mediante una exposición celebrada en 1983 en el Museo ${ }^{41}$. Para esta muestra, el Museo realizó 73 copias modernas, a partir de los clichés originales. Fotógrafo local de Zeanuri, desde 1904 hasta 1936, con una sensibilidad cercana a lo popular y alejada de pretensiones. Realizó numerosos retra- tos de los habitantes de Zeánuri, algunos tomados en el modesto estudio que habilitó en la boardilla de su comercio y otros en exteriores. Su fotografía es directa y su sencillez nos descubre una modernidad que se transmite de su mirada, pero también se distingue en la iconografía de los nuevos medios de transporte que iban llegando al pueblo, o en el empleo de recursos como la seriación, con una influencia cinematográfica. Otra parte de su producción mantiene el imaginario de la tarjeta postal, que él mismo editó, en una visión cercana al costumbrismo y con un componente de registro etnográfico, que lo perfila como documentalista. De hecho, muchas de sus fotografías aparecieron en publicaciones especializadas sobre etnología.

El Museo también procedió al copiado de los clichés para la formación del fondo Antonio de Guezala y Ayrivié (Bilbao, 1889-1956), con 108 piezas, fechadas hacia 1921-1927, que se presentó parcialmente coincidiendo con su exposición antológica en 1991-1992 ${ }^{42}$. Artista multidisciplinar, su producción fotográfica, al igual que el resto de su obra artística, se proyecta desde una perspectiva intimista y cotidiana, que gira en torno al mundo que le rodea y a su propia sensibilidad. En su fotografía se aprecia un interés por el estudio de la luz y los tiempos de exposición,

\footnotetext{
Felipe Manterola: Argazkiak = Fotografías (1904-1930), Museo de Bellas Artes de Bilbao, Bilbao, 1983. 42 Antonio de Guezala y Ayrivié, 1889-1956, comisariada por Pilar Mur. Las fotografías fueron colgadas en un
espacio ajeno a la muestra, sin embargo, algunas fotografías sí son publicadas en el catálogo de la exposición: P. MUR PASTOR, Antonio de Guezala (1889-1956), Museo de Bellas Artes de Bilbao = Bilboko Arte Ederretako Museoa, Bilbao, D. L. 1991.
} 
así como otras investigaciones que le llevan a resultados ajenos a la corrección técnica. Su obra, se revela como una opción estética adoptada a partir de la experimentación, que en ocasiones sobrepasa lo fotográfico y se traspasan a sus carteles y pinturas.

El fondo de Tomás de Acillona, fechado entre 1932 y 1957, es el único de esta época que cuenta con obra original. Con un número más reducido de piezas, 12 fotografías, pero de gran interés por tratarse de gomas bicromatadas, procedimiento que no es muy común, en parte por la dificultad técnica que entraña. Vinculada a este fondo, el Museo conserva otra goma bicromatada del músico Andrés Isasi, compañero de afición de Acillona, donada al tiempo que las anteriores, con motivo de la exposición Tomás de Acillona. Fotografías 1932-1957, en 2010³.

Las fotografías de Tomas de Acillona y Uría (Getxo, Bizkaia, 1893 - Biarritz, Francia, 1957) son una interpretación idealizada de la realidad, que el autor alteraba mediante los retoques que la goma bicromatada le permitía, introduciendo también tonalidades según el pigmento utilizado. Acillona entiende estas intervenciones como una expresión de creatividad artística, dentro de una concepción pictorialista. Sus imágenes finales ofrecen una estética suave, de bordes poco definidos y texturizada, con un cuidado tratamiento de las luces y de los volúmenes.

Avanzando cronológicamente, Josep Maria Ribas i Prous (Barcelona, 1940) fue el primero en ceder personalmente su obra al Museo de Bilbao. Se trata de un conjunto de 18 piezas, fechadas entre 1968 y 1981. Como se ha dicho, su donación se realiza a partir de la participación del autor en el certamen Arteder'82, que ganó con la pieza Els Peixos. La exposición que el Museo le dedicó fue llevada a cabo dos años después de la cesión de la obra ${ }^{44}$. Las fotografías que conserva el Museo responden mayoritariamente a una de sus temáticas más difundidas, el retrato femenino, en ocasiones desnudos, que emplea como excusa para una experimentación formal y con una gran precisión técnica. Se asemejan a bodegones

\footnotetext{
43 M. LERTXUNDI, Tomás de Acillona: Fotografias 1932-1957, Museo de Bellas Artes de Bilbao, Bilbao, 2010. 44 Josep Maria Ribas i Prous, «Guía de Exposiciones, 39», [Folleto], Museo de Bellas Artes de Bilbao, [Bilbao], octubre 1984 .
} 
a gran escala, en los que aplica distintas soluciones técnicas, como el empleo de flou, un grano muy marcado o virajes, prestando siempre una especial atención a las luces y su contraste.

En 1985, la muestra Gabriel Cualladó. Fotografias, dio pie a una nueva donación por parte del propio autor, que conforma un fondo de 17 obras, fechadas entre 1957 y $1981^{45}$. Gabriel Cuallado Candel (Massanassa, València, 1925-Madrid, 2003) formó parte del entorno de Afal, próximo al documentalismo de carácter humanista. $\mathrm{Su}$ obra se centra en el retrato. A través de sus fotografías, el autor trata de sacar a la luz la particularidad y la esencia del retratado, en tomas directas, sin simbolismos ni alegorías. Pese a lo dicho, lo que permanece en su obra es la sensibilidad del fotógrafo, que se revela en una cierta melancolía y una forma de poesía visual que la impregna.

El de Martínez Novillo, es uno de los pocos fondos fotográficos adquiridos por la institución. Está compuesto por 8 vistas, fechadas en $1968^{46}$. También cumple la particularidad de ser el único fondo formado exclusiva- mente por fotografía a color y de ser el único posterior a 1950 con copias modernas ${ }^{47}$. La galería Joan Gaspar, ya fallecido el autor, realizó una tirada de 10 copias, más 2 no venales, de una selección de sus fotografías a partir de la digitalización de las diapo- sitivas en kodachrome, su retoque y posterior impresión digital ${ }^{48}$.

La serie del pintor Cirilo Martínez Novillo (Vallecas, Madrid, 1921-Madrid, 2008) que conserva el Museo de Bilbao son paisajes de la ría del Nervión, en los que la suciedad y la contaminación del estuario se integran en las composiciones. Con ello, el autor capta los testimonios visibles de una problemática derivada del proceso de industrialización, que implicaban un conflicto territorial con varias ramificaciones, y que pocas veces fue captada de forma tan directa, al menos durante aquella época.

\footnotetext{
45 Gabriel Cualladó: Fotografias, Caja de Ahorros Vizcaína-Departamento de Cultural, Bilbao, 1985.

46 Cirilo Martínez Novillo: Fotografias color 1957/1970, Galería Joan Gaspar, Madrid; Barcelona, 2010.

$47 \quad$ El fondo Tomás de Acillona está compuesto de fotografías en color, realizadas mediante un procedimiento pigmentario y no mediante el uso de una película a color, como es el caso de las fotografías de Martínez Novillo. Sí encontramos una presencia importante de fotografía a color en el fondo de Alberto Schommer, que se combina con la de blanco y negro; mientras que el fondo Arteder' 82 contiene una única obra a color. Entre las obras sueltas, que no forman parte de ningún fondo fotográfico concreto, encontramos otras siete fotografías a color.

48 El fondo de Martínez Novillo no ha sido exhibido íntegramente, aunque una parte de sus fotografías sí han participado en exposiciones colectivas organizadas por el Museo.
} 
Uno de los fondos más destacados de la Colección de Fotografía del Museo de Bilbao es el de Alberto Schommer, y lo es tanto por sus particularidades físicas, por ser el más numeroso con el que cuenta la colección, así como por tratarse de un fotógrafo vasco con una larga trayectoria y reconocimiento internacional. Compuesto por 127 piezas, en formatos que van desde los 12 x $18 \mathrm{~cm}$ hasta los $110 \times 165 \mathrm{~cm}$. Esta diversidad también la encontramos en las técnicas, alternándose los procedimientos químicos con las impresiones digitales, coexistiendo la fotografía a color con la de blanco y negro. Entre ellas hay tanto copias y originales de época como copias modernas reinterpretadas por el autor. También su cronología es amplia, de 1952 a 2007. Así pues, se trata de un fondo representativo de la trayectoria de Schommer, siendo el Museo de Bilbao la institución que conserva un conjunto más completo de su obra. Su donación se dio de forma escalonada desde 2005 hasta 2013 y estuvo vinculada a la exposición retrospectiva que se le dedicó en $2010^{49}$.

La mayoría de la producción de Alberto Schommer García (Vitoria-Gasteiz, 1928 - San Sebastián, 10/09/2015) se plantea en series cerradas que el autor conceptualiza individualmente a partir de una idea previa de lo que quiere transmitir y emplea la técnica fotográfica de un modo expresivo para que refuerce esa noción. Frecuentemente, aplica recursos de la fotografía publicitaria y de moda, con los que busca causar asombro en el espectador. Su versatilidad se aprecia en la diversidad de las series del Museo.

Schommer pertenece a la misma generación de fotógrafos que Ribas i Prous y Cualladó, no obstante, por la cronología de las obras conservadas en el Museo, este fondo también es coetáneo a los de fotógrafos más jóvenes, sirviendo de engranaje entre ambas generaciones dentro de la Colección de Fotografía.

Los siguientes fondos, pertenecen a autores que inician su andadura fotográfica hacia finales de los años setenta y principios de los ochenta. Sus autores comparten las características de ser vizcaínos. Los tres conjuntos están compuestos de copias de revelado químico.

49 Schommer: Retrospectiva 1952 - 2009, Museo de Bellas Artes de Bilbao, Bilbao, 2010. 
El de Mikel Alonso (Bilbao, 1950) está formado por 16 obras donadas en 1985. Se trata de un proyecto de refotografía realizado en 1985 con motivo de la exposición Bilbao a fines del siglo XIX. En él se vuelven a registrar las vistas de las fotografías de Epalza, desde la misma perspectiva, evidenciando con ello los cambios a los que ha sido sometido el paisaje. Se distingue aquí una tímida iniciativa del Museo por promover la producción fotográfica.

El siguiente fondo fue el de Patxi Cobo, adquirido en 1990, con 49 copias de una serie de paisajes que es presentado en las salas del Museo ese mismo año ${ }^{50}$. La serie, tomada entre 1987 y 1990, aborda los usos y la forma de relacionarnos con el territorio a través del proceso de reapropiación de la vegetación de aquellos lugares primero explotados y, posteriormente, abandonados por la minería.

El último de los conjuntos es el de Luis María Izquierdo-Mosso (Sestao, Bizkaia, 1954), quien en 2002 dona la serie Seguir mirando de 1985, con un total de 67 fotografías, de las cuales 34, de menores dimensiones, forman parte de un álbum ${ }^{51}$. Se trata de una serie de retratos de artistas vascos, en los que el autor introduce la variante del componente autobiográfico, siendo su entorno lo que realmente retrata. Las fotografías se enmarcan dentro de una conceptualización general sobre el arte y los mecanismos de percepción, que pone en tela de juicio mediante incorrecciones técnicas y la dinamitación del género del retrato.

Hasta el momento se han mencionado catorce fondos fotográficos, tres colectivos y once de autores individuales, más cuatro obras sueltas anteriores a 1950, que fueron acogidas como parte de colecciones multidisciplinares. Completando la descripción de la Colección de Fotografía hay que añadir cuatro obras que pertenecen a la colección, Bilboko Tranbiarako 7 Irudi $=7$ Intervenciones plásticas para el tranvía de Bilbao, de 2002-2003, que fue un encargo de Ferrocarriles Vascos. Dos de ellas son de Eduardo Sorrouille y otras dos atribuidas a Fermín Moreno, quien presentó una instalación registrada mediante dos fotografías de Martín Egia.

\footnotetext{
50 Las copias que conserva el Museo de Bilbao no son las mismas que fueron expuestas. Patxi Cobo: Argazkiak= Fotografia, Museo de Bellas Artes de Bilbao = Bilboko Arte Ederretako Museoa, Bilbao, D.L. 1990.

51 Las fotografías de Izquierdo-Mosso nunca han sido expuestas en el Museo de Bellas Artes de Bilbao, sin embargo, sí lo fueron en la sala de exposición de la Caja de Ahorros Vizcaína y en la Casa de la Cultura de Basauri: L. M, IZQUIERDO-MOSSO, Luis María, Seguir mirando, Caja de Ahorros Vizcaína-Departamento de Cultura, Bilbao,1986.
} 
Completan la colección otras nueve obras sueltas, todas de fotógrafos actuales, que han ingresado en el Museo de forma independiente, la mayoría ya en el siglo XXI, y que no pertenecen a ningún conjunto. En estos casos los autores trabajan frecuentemente con técnicas digitales. Entre este grupo encontramos un mayor porcentaje de fotografía a color: dos fotografías de Alfonso Batalla, una de Ixone Sádaba, una de Chema Alvargonzález, dos de Fermín Moreno y otra de Tania Argandoña. Los dos montajes fotográficos de Heinz Hebeisen, una fotografía de Jesús Ángel Miranda y otra de Leire Ajuriagoxeascoa están realizadas en blanco y negro. Estas obras han sido mayoritariamente enviadas al Museo por los autores o por instituciones. Ninguna de estas obras ha sido expuesta en el Museo de Bilbao hasta el momento.

\section{La fotografía en el Archivo del Museo de Bellas Artes de Bilbao}

La presencia de la fotografía dentro del Museo no sólo se limita a las colecciones, sino que también se encuentra en su Archivo. El propio Museo ha generado a lo largo de su historia una gran cantidad de imágenes con una finalidad de registro. Además de éstas, encontramos otros objetos fotográficos que han ingresado como documento gráfico en el Archivo del Museo de Bellas Artes de Bilbao pero que, al mismo tiempo, comparten un interés histórico y estético, por encima del documental.

Se trata de un álbum fotográfico de los hermanos Ramón y Valentín Zubiaurre, fechado entre 1899 y 1901. Está compuesto por 56 obras, y responde a una tipología de álbumes que tuvieron un gran auge entre la alta burguesía en la Inglaterra decimonónica. Las fotografías son escenificaciones costumbristas que tienen un carácter narrativo, que se enfatiza mediante leyendas escritas sobre el soporte secundario. Es remarcable el hecho de que no haya sido desmembrado, aunque faltan dos fotografías, ya que son pocos los álbumes fotográficos que han llegado hasta nuestros días completos.

El segundo es el conjunto documental fotográfico Ricardo Bastida, arquitecto bilbaíno. Tiene la característica de estar compuesto por clichés y positivos en 
placas de vidrio y en papel, siendo las únicas fotografías sobre vidrio del Museo. Está fechado hacia la primera década del siglo XX.

El tercero es una serie realizada por Patxi Cobo que responde al encargo del Museo para documentar la reforma de ampliación del edificio del Museo, entre 1997 y 2001. El conjunto está conformado por copias a color y en blanco y negro, y una selección de las mismas fue expuesta en la muestra Museo, un espacio transformado, en $2002-2003^{52}$.

\section{Recapitulación y análisis de la Colección de Fotografía}

La complejidad de la fotografía como objeto mecánico creativo ha comportado un cierto conflicto a la hora de ser acogida por los museos, tanto por la resistencia a ser considerada pieza museable como por la dificultad de adaptarla a los mecanismos de catalogación y de conservación habituales en estas instituciones. Con todo ello, a principios de los noventa, la presencia de la fotografía en los suaeos seguía siendo excepcionas, y todavía más que un museo tuviera una política activa respecto a su preservación y difusión, como era el caso del Museo de Bellas Artes de Bilbao. A lo que hay que añadir, el hecho de que no se tratara de un museo dedicado específicamente al arte contemporáneo.

La Colección de Fotografía del Museo de Bellas Artes de Bilbao se gesta a principios de la década de 1980 como resultado de una gestión que se encauzaba a la puesta en valor,la conservación y la difusión el medio fotográfico.

Una de las estrategias principales de la institución fue la de acoger en su seno una importante actividad expositiva, en la que se combinaba la obra de ámbito estatal y la de autores internacionales, y de distintas épocas, desde los fotógrafos españoles emergentes, hasta aquellas figuras clave en la evolución de la Historia de la Fotografía que contaban con un reconocimiento internacional. Con ello, el Museo llevó a cabo una labor fundamental en la puesta al día de la comunidad sobre el legado fotográfico.

52 COBO, P., Museo, un espacio transformado, Museo Bellas Artes Bilbao, [Bilbao], 2002. 


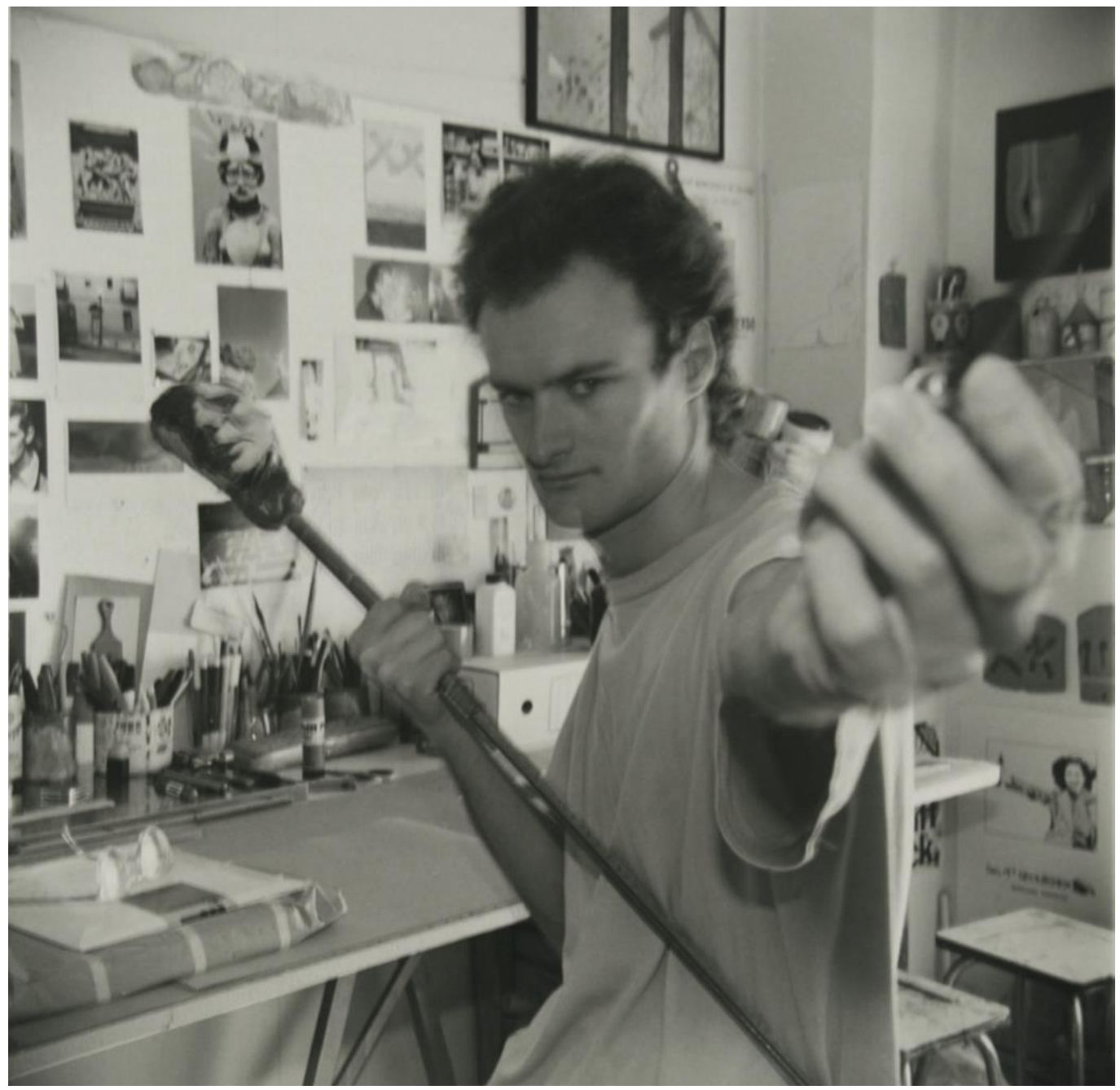

Fig. 5. Luis María Izquierdo-Mosso, Autorretrato, 1985, Museo de Bellas Artes de Bilbao 
La asiduidad y la relevancia de las muestras fotográficas ofrecidas al público vizcaíno hasta mediados de la década de los noventa revelan su actividadexpositiva como una de las más destacadas de España en aquel período. Mediante esta labor de difusión, además, se fomentó la equiparación de la fotografía al mismo rango que otras formas de expresión creativa, que eran expuestas en paralelo.

La conciencia de la institución hacia la conservación de la fotografía y sus propósitos de consolidar la Colección de Fotografía se evidencia en la propuesta de creación de un departamento especializado en 1983, un año antes que los museos españoles más avanzados, como el MNCARS o la Fundació Miró, si bien no llegó a concretarse, como tampoco sucedió en los otros dos casos. A pesar del fallido intento de creación de un departamento específico, el Museo de Bellas Artes de Bilbao no cejó en su empeño de dar un espacio a la fotografía en sus colecciones, que se vieron ampliadas en 11 fondos fotográficos desde 1980 hasta 1997, de un total de 14 que conserva hoy en día. Como parte de este esfuerzo cabe destacar la investigación y la recuperación de autores vizcaínos, cuyos archivos eran desconocidos hasta el momento. Desgraciadamente, tras este período de expansión, no volvemos a encontrar entradas significativas de foto- grafía hasta el 2002 y el 2010, con la recepción de otros tres fondos.

En cualquier caso, la actividad del Museo de Bellas Artes de Bilbao se revela como una de las instituciones pioneras en la conservación, difusión y puesta en valor del medio, dentro de nuestras fronteras, con un claro empeño por situar a la fotografía a la altura de otras formas de expresión artística. Un papel que no ha sido recogido por la bibliografía que aborda estos aspectos historiográficos.

La composición de la Colección de Fotografía del Museo de Bellas Artes de Bilbao lo caracteriza por la disparidad de los fondos que la componen, y por su amplio arco cronológico, que va de finales del siglo XIX al año 2007, siendo Enrique Epalza y Alberto Schommer los dos extremos del mismo ${ }^{53}$. Igualmente, el contexto geográfico varía entre los distintos fondos, que pueden ser de ámbito regional, estatal

53 Este marco cronológico abarca únicamente los fondos fotográficos con entidad propia, y no las fotografías sueltas, entre las que se encuentra Laureano de Jado a los 19 años y tres meses, fechada en 1862. 
o internacional, si bien predomina la fotografía vasca, con 9 fondos de un total de 14 , frente a 3 estatales y 2 con presencia de autores internacionales.

A pesar de la heterogeneidad de los conjuntos de la Colección y de sus autores, se puede trazar una línea entre los distintos fondos, según el contexto cronológico y, en segundo término, espacial.

Enrique Epalza, Felipe Manterola, Antonio de Guezala y Tomás de Acillona, son los primeros cuatro autores, anteriores a la década de 1950, todos ellos vizcaínos. Pese a las diferencias estéticas de su obra, su producción bascula entre la idea de modernidad y la de tradición. La primera como sinónimo de progreso y bienestar, vinculada al desarrollo económico y al proceso de industrialización, que transformó radicalmente la vida del entorno de la ría del Nervión y el paisaje de la región, llegando a ser una seña de identidad para sus habitantes, cuyas implicaciones seguirán vigentes en el imaginario de finales de siglo. La segunda, como reflejo de esas formas de vida que estaban desapareciendo ante la imposición de las innovaciones, que discurre entre una cierta añoranza y un cierto exoticismo ligado al costumbrismo.

Se trata de un binomio que es común a la sociedad, a la cultura y las expresiones artísticas de la época, desde la generación del 98, con su ideario regionalista, hasta los movimientos vanguardistas, con la ciudad como tema. A través de sus fotografías, cada uno de los autores ofrece una perspectiva distinta sobre estas cuestiones, en las que también confluyen sus propios intereses personales y un contexto concreto, en distinto cada caso.

Los siguientes fondos corresponden a autores de ámbito estatal, que iniciaron y desarrollaron su obra fotográfica principalmente desde los años cincuenta hasta los setenta. Entre ellos encontramos a Gabriel Cualladó, Josep Maria Ribas i Prous y Alberto Schommer ${ }^{54}$. Los tres tienen una concepción personal de la fotografía, con la que buscaban una forma de expresión propia y subjetiva. Desde este posicionamiento, pretendían contrarrestar el conservadurismo de los lenguajes fotográficos que predominaron en el contexto de las décadas de los cincuenta y los sesenta.

54 Aunque Alberto Schommer era vasco, su producción fotográfica tuvo una clara proyección estatal. 
Esta generación de autores, será fundamental en la evolución de la concepción de la fotografía, sin embargo, mantienen una distancia con la generación de fotógrafos que surgirá a partir de 1970, en la que se aprecia nuevas influencias.

El fondo Arteder'82 se encuadra a medio camino entre dos generaciones y la siguiente, pero en un ámbito de la fotografía lituana, lo cual nos permite trazar conexiones con sus coetáneos españoles. Así, se encuentran puntos en común entre Antanas Sutkus y Gabriel Cualladó, ambos retratistas de primer orden en sus respectivos contextos. Mientras que en la obra de Milda Drazdauskaite, de una generación posterior, la eliminación del límite entre lo personal y el grupo, como identidad, está en perfecta sintonía con la serie Seguir mirando, de Luis IzquierdoMosso, dentro de la visión postestructuralista que surge en los años setenta.

Por su lado, las fotografías de Cirilo Martínez Novillo, a modo de excepción, parece alejada de las concepciones fotográficas de su generación, y su obra se adelanta en la forma de registrar el paisaje y su problemática, que será central en los fotógrafos posteriores.

Así se aprecia en los fondos de Mikel Alonso, Patxi Cobo y Bilbao, ría de hierro. Los tres hondan en el tema del paisaje desde distintas estrategias, en consonancia con los replanteamientos del género que se dan desde finales de la década de 1970 a nivel internacional. Se trata de una respuesta ante los cambios acontecidos por la expansión urbana en conjunción con la crisis industrial, que se evidencia especialmente en las zonas que experimentaron una fuerte industrialización, como es el caso del Bilbao metropolitano.

Por su parte, Cinco años de prensa gráfica se distancia de los parámetros seguidos por las instituciones museísticas en la conservación fotográfica, principalmente por su función. Si bien se trata de un ejemplo notable dentro del fotorreporterismo, que responde a un momento clave en la evolución del lenguaje del periodismo gráfico.

Como se ha ido viendo, cada uno de los fondos hace una aportación particular a la Colección y la definen en su pluralidad. Si bien puede parecer un tanto desarticulada a primera vista, la heterogeneidad que la caracteriza forma parte de su riqueza. Al mismo tiempo, la Colección de Fotografía debe ser entendida como una pieza que complementa la diversidad de disciplinas del resto de las colecciones del Museo. 
Por último, cabe hacer hincapié en la importancia del Museo de Bellas Artes de Bilbao en su papel como promotor de la integración de la fotografía en instituciones museísticas, y en la aportación que supone el conocimiento de esta Colección, que ha sido poco difundida hasta el momento, dentro de esa cartografia del Patrimonio Fotográfico Español. 